\title{
AS PRIMEIRAS FICHAS DO MODERNISTA MÁRIO DE ANDRADE
}

\author{
Tatiana Longo Figueiredo \\ tatianalongo@usp.br
}

\section{ESPONJA DE IDEIAS}

Que mistério, que intuição, que anjo-da-guarda, Oneida, quando aos 16 anos e muito resolvi me dedicar à música, me fez concluir instantaneamente que a música não existe, o que existia era a Arte?... E desde então, desde esse primeiro momento de estudo real [...] assim como estudava piano, não perdia concerto e lia a vida dos músicos, também não perdia exposições plásticas, devorava histórias de arte, me atrapalhava em estéticas mal compreendidas, estudava os escritores e a língua, e, com que sacrifícios nem sei pois vivia de mesada miserável, comprava o meu primeiro quadro!

Carta de Mário de Andrade a Oneyda Alvarenga; Rio de Janeiro, 14 set. 1940 (ALVARENGA, 1983, p. 270-271).

Nesta epígrafe que escolhi para meu trabalho, encontra-se, nas palavras de Mário de Andrade, o broto de onde despontou, como prodigiosa ramificação, o polígrafo. A declaração permite que se infira que, para o jovem, logo tenha surgido a necessidade de sistematizar seus estudos em fichas, evitando, assim, a possível dispersão. Pode-se pensar que essa solução decorreu de instruções de seu primo e amigo Pio Lourenço Corrêa, fazendeiro e intelectual de Araraquara, além de inveterado leitor, apaixonado por questões linguísticas que possuía um considerável fichário sobre o assunto; ou de noções recebidas, talvez, de 
seus professores franceses e belgas, na Faculdade de Filosofia e Letras de São Paulo, no Mosteiro de São Bento, vinculada à Universidade de Louvain. Isso seria aqui, todavia, uma impertinente digressão. A verdade é que, no Arquivo Mário de Andrade, o Fichário analítico, construído durante mais de duas décadas, reúne fichas de leitura, notas de trabalho, cartas, esboços de ideias, matérias extraídas de jornais e revistas, formando uma espécie de enciclopédia para uso próprio, backup da memória que respaldou a criação do polígrafo e serviu a seus amigos. Conservado no Instituto de Estudos Brasileiros da Universidade de São Paulo, hoje alimenta inúmeras pesquisas, nas áreas que o compõem. Guarda 9.634 documentos organizados por assunto, em dez divisões: Obras Gerais, Música, Literatura, Artes Plásticas, Estética, Filosofia e Religiões, Ciências, Psicologia e Etnografia, Sociologia e História Universal e do Brasil -, cada qual com subdivisões. As primeiras fichas do Fichário analítico datam, provavelmente, do início da década de 1920. Surgem talvez como resposta a uma necessidade criada durante a redação do "Prefácio interessantíssimo" de Pauliceia desvairada, o primeiro livro assinado pelo poeta modernista, em 1922, depois de Há uma gota de sangue em cada poema, em que, sob o pseudônimo Mário Sobral, já arriscara passos nessa direção, quatro anos antes.

\section{GANHA CORPO A DESVAIRADA PAULICEIA}

Em 20 de maio de 1928, escrevendo a Augusto Meyer (FERNANDES, 1968, p. 50-51), Mário de Andrade conta ao amigo circunstâncias da criação de Pauliceia desvairada ou simula uma versão. Coincidindo com este relato, muitos anos depois, a conferência $O$ movimento modernista ${ }^{1}$ também traz a história da gênese de Pauliceia desvairada², considerada a encenação na construção da memória:

Eu passara esse ano de 1920 sem fazer poesia mais. Tinha cadernos e cadernos de coisas parnasianas e algumas timidamente simbolistas, mas tudo acabara por me desagradar. Na minha leitura desarvorada, já conhecia até alguns futuristas de última hora, mas só então descobrira Verhaeren. E fora o deslumbramento. Levado em principal pelas Villes Tentaculaires, concebi

1. Conferência proferida em 30 de abril de 1942, no Ministério das Relações Exteriores do Brasil, no Palácio Itamarati, no Rio de Janeiro, então Distrito Federal.

2. Há que se abrir parênteses aqui para dizer que o título parte da blague explorada pelo autor em seu "Prefácio interessantíssimo", mas também serve, em contraponto, a retratar o eu lírico como o vate ou louco, aquele que por sua loucura tem a capacidade de descortinar a verdade. 
imediatamente fazer um livro de poesias "modernas", em verso-livre, sobre minha cidade. Tentei, não veio nada que me interessasse. Tentei mais, e nada. Os meses passavam numa angústia, numa insuficiência feroz. Será que a poesia tinha se acabado em mim?... [...]

Foi quando Brecheret me concedeu passar em bronze um gesso dele que eu gostava, uma Cabeça de Cristo [...] Eu devia os olhos da cara! Andava às vezes a pé por não ter duzentos réis pra bonde, no mesmo dia em que gastara seiscentos mil-réis em livros... E seiscentos mil-réis era dinheiro então. Não hesitei [...] e afinal pude desembrulhar em casa a minha Cabeça de Cristo, sensualissimamente feliz. Isso a notícia correu num átimo, e a parentada que morava pegado, invadiu a casa pra ver. E pra brigar. Berravam, berravam. Aquilo era até pecado mortal! estrilava a senhora minha tia velha, matriarca da família. Onde se viu Cristo de trancinha! era feio! medonho! Maria Luísa, vosso filho é um "perdido" mesmo.

Fiquei alucinado, palavra de honra. Minha vontade era bater. Jantei por dentro num estado inimaginável de estraçalho. Depois subi para o meu quarto, era noitinha, na intenção de me arranjar, sair, espairecer um bocado [...] Eu estava aparentemente calmo, como um indestinado. Não sei o que me deu. Fui até a escrivaninha, abri um caderno, escrevi o título em que jamais pensara, Pauliceia desvairada. O estouro chegara afinal, depois de quase ano de angústias interrogativas. Entre desgostos, trabalhos urgentes, dívidas, brigas, em pouco mais de uma semana estava jogado no papel um canto bárbaro, duas vezes maior talvez do que isso que o trabalho de arte deu num livro (ANDRADE, s.d., p. 233-234).

Se na época não havia qualquer facilidade para copiar textos no intuito de divulgá-los entre os amigos, as obras dos modernistas eram compartilhadas em leituras nas reuniões dos grupos de São Paulo e do Rio de Janeiro. Recebida com admiração e entusiasmo, a leitura do manuscrito de Pauliceia desvairada ilumina uma vereda aos companheiros que propunham uma nova estética. No entanto, os modernistas não pretendiam ficar restritos ao grupo e dessas reuniões saiu como fruto a Semana de Arte Moderna, realizada no Teatro Municipal de São Paulo entre 11 e 17 de fevereiro de 1922. Com exposição de artes plásticas, conferências, leitura de poemas e apresentações musicais, o evento foi bastante noticiado e mesmo achincalhado pela grande imprensa, conforme se pode acompanhar em 22 por 22: a Semana de Arte Moderna vista pelos seus contemporâneos, pesquisa de Maria Eugenia Boaventura (200o). Revelou-se, com o tempo, marco fundamental das artes no Brasil. Cabe ressaltar que, ainda hoje, após 90 anos da Semana de Arte Moderna, muito "folclore" é repisado como a história de que Mário de Andrade, na ocasião, teria declamado "Ode ao burguês" nas escadarias do Teatro Municipal. "A jovem literatura brasileira”, artigo de Sérgio Milliet no primeiro número da revista belga Lumière, em novembro de 1922 (BOAVENTURA, 2000, p. 161-173), testifica que a plateia ouviu o poema 
"Domingo" de Pauliceia desvairada, estocada menos agressiva que "Ode ao burguês", porque envolta em metáforas.

Para chamar a atenção, quase um ano antes da Semana de Arte Moderna, Oswald de Andrade publicara, em 27 de maio de 1921, no Jornal do Comércio de São Paulo, "O meu poeta futurista", estampando o poema "Tu" do livro ainda inédito Pauliceia desvairada. A menção ao termo "futurista", que, por si própria, já causaria escândalo, mais ainda causou ao se somar aos versos livres de Mário e à provocação de Oswald ao leitor: "Acharam estranho o ritmo, nova a forma, arrojada a frase? Graças a Deus”. Dias depois, pelo mesmo jornal, em "Futurista?!"3, Mário de Andrade defende o "autor de Pauliceia desvairada" e, ao esclarecer sua posição e a desse "amigo", como modernistas brasileiros, repudia qualquer filiação à escola italiana de Marinetti. Ressalta, aliás, que o "amigo" não "tinha e não tem ainda nenhuma intenção" de publicar Pauliceia desvairada. Ao mesmo tempo, contraditoriamente, Monteiro Lobato, editor, tinha em mãos os originais de Pauliceia desvairada; confessa não ter entendido os versos e se recusa a publicar o livro sem um prefácio que explicasse a nova poética. Mário relembra a história em seu artigo "Literatura", no Diário de Notícias de 26 de maio, 1940 (ANDRADE, 1993, p. 194-198). O esforço de síntese ao sinalizar influências e diálogos e citar trechos, testemunhando o contato com as vanguardas europeias por meio de atualizadas leituras, teria sido a mola propulsora do "Prefácio Interessantíssimo".

Na correspondência de Mário de Andrade, encontra-se a carta de Monteiro Lobato, escrita em 17 de setembro de 1921, na qual o editor desiste de publicar Pauliceia desvairada:

Prezado amigo Mário/ Estive relendo a tua Pauliceia e... fiquei sem coragem de editá-la. Está uma coisa tão revolucionária que é capaz de indignar a minha clientela burguesa e fazê-los lançar terrível anátema sobre todas as produções da casa. Levando-nos à falência. Não sou dos menos corajosos, mas confesso que neste caso a coragem falece-me por completo... Acho que o melhor é tu mesmo editares o vermelho grito de guerra./ Vamos. Resolve lá este caso./ Lobato ${ }^{4}$.

Cristalizada a recusa, no próprio papel da carta assinada por Lobato está o testemunho de Mário de Andrade: "Respondido: S.P. 18/9/921/ Lobato/ Previsão utilíssima. Peço entregar manuscrito ao portador./ 'Addio senza rancore'./ Mário de Andrade”.

3. ANDRADE, Mário de. "Futurista?!" Jornal do Comércio. São Paulo, 6 de junho de 1921 (série Matéria extraída de publicações, Arquivo Mário de Andrade, IEB-USP).

4. Documento na série Correspondência, Arquivo Mário de Andrade, IEB-USP. 
"O vermelho grito de guerra" sai, em 21 de julho de 1922, no volume editado às expensas de seu autor nas oficinas da Casa Mayença Editora.

\section{O INÍCIO DO FICHÁRIO ANALÍTICO}

Não era fácil acompanhar em livros e revistas a efervescência das vanguardas europeias e a tarefa se complicava sobremodo para um intelectual no Brasil. Cabe destacar que Mário de Andrade nunca foi à Europa, centro cultural da época, e que essas publicações raramente chegavam ao mercado brasileiro. Para importar era preciso ter em mãos o nome das editoras e os títulos desejados, conforme relata Mário de Andrade, na carta dirigida a Joaquim Inojosa, em 28 de novembro de 1924:

\footnotetext{
Pra nós brasileiros é uma dificuldade enorme saber exatamente quais as teorias modernistas da Europa e dos Estados Unidos, porque os livros que tratam delas não são livros de exportação. É preciso ter essa paciência enorme de mandar buscá-los, catando aqui e além no jardinzinho das capelas artísticas o que há de mais importante e mais útil (INOJOSA, 1969).
}

Assim, para obtê-los e manter-se atualizado, Mário de Andrade empenha-se em assinar diversas revistas estrangeiras que resenhavam os mais recentes títulos. Entre eles destaca-se a revista francesa L'Esprit Nouveau.

Lilian Escorel, em L'Esprit Nouveau nas estantes de Mário de Andrade ${ }^{5}$, recupera matrizes da criação de Mário de Andrade nas anotações de leitura deixadas nas margens dos exemplares da coleção da revista que a ele pertenceu.

De minha parte, encontro nas fichas relacionadas à revista L'Esprit Nouveau a possibilidade de serem elas os documentos iniciais do Fichário analítico. Penso que são, no entanto, posteriores à redação do "Prefácio Interessantíssimo" de Pauliceia desvairada. Ao escritor, a tarefa de recorrer a todo o arsenal evocado no "Prefácio interessantíssimo", sem fichas de leitura, foi, por certo, de difícil execução. É justamente ao imaginar essa árdua tarefa que formulo a hipótese de que a necessidade levou Mário de Andrade a reunir coerentemente suas leituras em fichas, de separá-las em assuntos principais, temas e subtemas, ordenados por identificação

5. Publicação da tese L’Esprit Nouveau na formação das ideias estéticas e da poética de Mário de Andrade, orientada por Telê Ancona Lopez e defendida na Universidade de São Paulo, em 2009. 
numérica. As fichas, encimadas por tópicos bastante amplos, poderiam ser incrementadas em leituras posteriores e, assim, estariam sempre prontas a servir. Se, na maior parte das vezes, um livro trata de assunto único, ou possui tema central, uma revista traz, nos textos, distribuídos nos vários números lançados durante anos, uma constelação de autores e vasta quantidade de assuntos explorados em diversas nuanças. Talvez, naquele momento, tenha saltado aos olhos de quem estava formando uma grande biblioteca o quanto, com o passar do tempo, a tarefa de recorrer a esses textos se complicaria sem fichas de leitura. O escritor/ leitor desenvolveu, então, um método que passou a explorar, conforme a "Advertência" de seu livro Namoros com a medicina, datada de 1937:

Minha maneira de trabalhar é assim: vou lendo, desgraçadamente sem muito método, aquilo que pelo seu autor ou seu assunto me dá gosto, ou responde às perguntas do meu ser muito alastrado. Como desde muito cedo tive memória pouca mas estimo ter resposta pronta às minhas perguntinhas, tomei por hábito virtuoso fichar (ANDRADE, 1980, p. 6).

Dentre os registros no Fichário analítico a respeito do assunto Literatura, na subdivisão Poesia, dois ligam-se claramente ao "Prefácio interessantíssimo", na chave, contudo, da organização das ideias bebidas em L'Esprit Nouveau. A primeira é a ficha no 3418 , em cujo cabeçalho está "Poesia (que é)" e entre as anotações telegráficas traz a indicação: "Que é P. Dermée E. N. 3 p. 327", ou seja, a definição de poesia em "Poésie = lyrisme + art", texto assinado por Paul Dermée, no terceiro número de L'Esprit Nouveau, Paris, [dezembro de 1920] ${ }^{6}$. A segunda, a ficha no 3536, intitulada "Lirismo", remete novamente à fórmula de Paul Dermée: "Poesia = Lirismo + Arte". As fichas ligam-se à nota de rodapé deste trecho do "Prefácio interessantíssimo":

A inspiração é fugaz, violenta. Qualquer empecilho a perturba e mesmo emudece. Arte, que, somada a Lirismo, dá Poesia ${ }^{7}$, não consiste em prejudicar a doida carreira do estado lírico para avisá-lo das pedras e cercas de arame do caminho. Deixe que tropece, caia e se fira. Arte é mondar mais tarde o poema de repetições fastientas, de sentimentalidades românticas, de pormenores inúteis ou inexpressivos (ANDRADE, 1922, p. 15-16) .

6. Esta e outras datas de publicação da revista L'Esprit Nouveau foram atestadas pela pesquisa de Lilian Escorel.

7. Nota MA: Lirismo + Arte = Poesia, fórmula de P. Dermée.

8. Anos depois, em A escrava que não é Isaura: discurso sobre algumas tendências da poesia modernista, publicado em 1925, Mário de Andrade propõe uma correção à fórmula de Paul Dermée: "Lirismo puro + Crítica + Palavra = Poesia" (ANDRADE, 2010, p. 14). 
Na mesma ficha, no 3536, a menção a "Fenomeno literario Epstein E.N.", relaciona-se ao texto "Le phénomène littéraire" de Jean Epstein, publicado em partes nos números 8,9 , 10, no número duplo 11/12 e no no 13 da L'Esprit Nouveau.

No "Prefácio interessantíssimo", Mário de Andrade traduz trecho do ensaio de Epstein, "Le phénomène littéraire", no n ${ }^{\circ} 10$ da revista L'Esprit Nouveau, de [julho de 1921], trecho que exibe traço de destaque do seu lápis, à margem, no exemplar que lhe pertenceu. Eis o trecho traduzido em Pauliceia desvairada:

\begin{abstract}
"Alguns leitores ao lerem estas frases (poesia citada) não compreenderam logo. Creio mesmo que é impossível compreender inteiramente à primeira leitura pensamentos assim esquematizados sem uma certa prática. Nem é nisso que um poeta pode queixar-se dos seus leitores. No que estes se tornam condenáveis é em não pensar que um autor que assina não escreve asnidades pelo simples prazer de experimentar tinta; e que, sob essa extravagância aparente havia um sentido porventura interessantíssimo, que havia qualquer coisa por compreender". João Epstein (ANDRADE, 1922, p. 13).
\end{abstract}

Outra parte do mesmo texto de Epstein, na continuação no número duplo 11/12, ficou assinalada por Mário de Andrade. Na margem, o traço, desta vez, combina-se com a constatação: "Mon Harmonismo!!!"

No "Prefácio interessantíssimo" de Pauliceia desvairada, na parcela em que o teórico do modernismo brasileiro organiza sua teoria sobre o verso melódico (sequência de palavras que formam uma sentença com sentido pleno), o verso harmônico (cada palavra do verso lançada sem completar o sentido da anterior, fazendo com que todas permanecessem vibrando, como sons), a polifonia poética, que seria constituída por frases soltas vibrando ao mesmo tempo (ANDRADE, 1922, p. 23-30), em seguida, para "ajuntar à teoria", continua:

Os gênios poéticos do passado conseguiram dar maior interesse ao verso melódico, não só criando-o mais belo, como fazendo-o mais variado, mais comotivo, mais imprevisto. Alguns mesmo conseguiram formar harmonias, por vezes ricas. Harmonias porém inconscientes, esporádicas. Provo inconsciência: Victor Hugo, muita vez harmônico, exclamou depois de ouvir o quarteto do Rigoletto: "Façam que possa combinar simultaneamente várias frases e verão de que sou capaz" (ANDRADE, 1922, p. 26).

Ainda quanto ao assunto, uma nota de rodapé no "Prefácio interessantíssimo" lança o foco sobre "Le phénomène littéraire" de Jean Epstein, sobre a revista L'Esprit Nouveau e, ainda, sobre a atualidade e a sintonia do escritor brasileiro com o que se teorizava nos meios culturalmente privilegiados: 
Há 6 ou 8 meses expus esta teoria aos meus amigos. Recebo agora, dezembro, número 11 e 12, novembro, da revista Esprit Nouveau. Aliás, Esprit Nouveau: minhas andas neste "Prefácio Interessantíssimo". Epstein, continuando estudo "O Fenômeno Literário" observa o harmonismo moderno, a que denomina simultaneismo. Acha-o interessante, mas diz que é "utopia fisiológica". Epstein no mesmo erro de Hugo (ANDRADE, 1922, p. 30).

Aproximando Jean Epstein e Victor Hugo, Mário de Andrade entende que a adesão às vanguardas não exclui a compreensão da lição do passado, como afirma no "Prefácio interessantíssimo": "O passado é lição para se meditar" (ANDRADE, 1922, p. 35). Posição, aliás, diametralmente oposta àquela defendida pelo futurismo de Marinetti.

A ficha no 4521, relacionada com o assunto Artes Plásticas, tendo no cabeçalho "Ozenfant-Jeanneret", destaca o artigo "Sur la plastique" publicado no primeiro número de L'Esprit Nouveau, o qual ecoa, também, no "Prefácio interessantíssimo".

No entanto, apesar de estas e as duas fichas do Fichário analítico ligadas à Literatura já analisadas mostrarem elementos explorados no texto que introduz Pauliceia desvairada, creio que o momento da redação do "Prefácio interessantíssimo" não contou com fichas. A afirmação consolida-se no fato de ser também de L'Esprit Nouveau a referência cristalizada no prefácio, mas sem qualquer rastro no Fichário analítico: “'O fato duma obra se afastar de preceitos e regras aprendidas, não dá a medida do seu valor"” (ANDRADE, 1922, p. 13-14). Trata-se de citação traduzindo a frase grifada por Mário de Andrade no texto "Gongora et Mallarmé” de Zdislas Milner, publicado no terceiro número da revista L'Esprit Nouveau, [dezembro de 1920].

No exemplar do no 2 da revista L'Esprit Nouveau, [novembro de 1920], que pertenceu a Mário de Andrade, em frase grifada no artigo "L'expressionnisme dans l'Allemagne contemporaine", assinado por Raymond Lenoir, Lilian Escorel encontrou a matriz do fragmento do "Prefácio interessantíssimo": "A poesia... 'tende a despojar o homem de todos os seus aspectos contingentes e efêmeros, para apanhar nele a humanidade"' (ANDRADE, 1922, p. 9-10). Matéria não destacada no Fichário analítico.

Também não se encontram fichas recuperando citações textuais garimpadas pelo escritor em livros, outras matrizes do "Prefácio interessantíssimo", em leituras anotadas ou sem marcas na biblioteca de Mário de Andrade. É o caso da epígrafe: "Dans mon pays de fiel et d'or j'en suis la loi” (ANDRADE, 1922, p. 7), retirada do $3^{\mathbf{0}}$ verso da última 
estrofe do poema “Celui du rien” do poeta belga Émile Verhaeren. Mário também se vale de Le style moderne de Emile Bayard ${ }^{10}$, de onde pinça a afirmação: “O fim lógico dum quadro é ser agradável de ver. Todavia comprazem-se os artistas em exprimir o singular encanto da feiúra. O artista sublima tudo"' (ANDRADE, 1922, p. 17-18). Cita fragmento do livro Philosophie de l'art de Taine ${ }^{11}$, versos de Alfred Musset ${ }^{12}$, verso de La Divina Commedia de Dante Alighieri'³ e, em "Andarei a vida de braços no ar, como o Indiferente de Watteau” (ANDRADE, 1922, p. 13), remete à tela assim intitulada, cuja contemplação se dá, não no Louvre, mas no livro Watteau: huit reproductions fac-simile en couleurs, exemplar em sua biblioteca.

Desse modo, julgo que a redação do "Prefácio interessantíssimo" teria desencadeado os primeiros registros do Fichário analítico, vinculados à revista L'Esprit Nouveau. A prática abrangeria logo outras revistas.

\section{REFERÊNCIAS BIBLIOGRÁFICAS}

ALVARENGA, Oneyda (org.). Mário de Andrade e Oneyda Alvarenga: cartas. São Paulo: Duas Cidades, 1983.

ANDRADE, Mário de. A escrava que não é Isaura. Rio de Janeiro: Nova Fronteira, 2010. . Aspectos da literatura brasileira. São Paulo: Livraria Martins Editora, s.d. . Namoros com a medicina. $4^{\underline{a}}$ ed., São Paulo/ Belo Horizonte: Martins/ Itatiaia, 1980 .

9. Do livro Les apparus dans mes chemins (1891), na biblioteca de Mário no terceiro dos quatro volumes de Poèmes, $7^{\underline{a}}$ ed., Paris: Mercure de France, 1912.

10. Na biblioteca de MA está a edição francesa, Paris: Garnier Frères, 1919.

11. No "Prefácio interessantíssimo", adaptação de Mário de Andrade do capítulo "De la nature de l'oeuvre d'art", do livro Philosophie de l'art de Hippolyte A. Taine (23 $3^{\underline{a}}$ ed., Paris: Hachette, t. I, cap. V, p. 41-42): "Taine disse que o ideal dum artista consiste em 'apresentar, mais que os próprios objetos, completa e claramente qualquer característica essencial e saliente deles, por meio de alterações sistemáticas das relações naturais entre as suas partes, de modo a tornar essa característica mais visível e dominadora” (ANDRADE, 1922, p. 16-17).

12. "L'art de servir à point un dénovement bien cuit" (ANDRADE, 1922, p. 21), adaptação do $5^{\circ}$ e 6 ํ versos da primeira estrofe do poema "Une soirée perdue"; "Sinto que o meu copo é grande demais para mim, e inda bebo no copo dos outros" (ANDRADE, 1922, p. 23), variação sobre o verso 82 de "La coupe et les lèvres".

13. A citação no "Prefácio interessantíssimo" "me parto por essa selva selvagem da cidade" (ANDRADE, 1922, p. 36-37) é a tradução do verso 5 do canto I da parte "Inferno" de La Divina Commedia de Dante Alighieri. O exemplar de Mário de Andrade, da edição de Fratelli Treves, Milão, é de 1908. 
. Pauliceia desvairada. $1^{\underline{a}}$ ed. São Paulo: Casa Mayença Editora, 1922. In: Caixa modernista. Jorge Schwartz (org.). São Paulo: Edusp/ Imprensa Oficial do Estado de São Paulo, Belo Horizonte: Editora UFMG, 2003.

. Vida literária. Pesquisa, estabelecimento de texto, introdução e notas por Sonia Sachs. São Paulo: Hucitec; Edusp, 1993.

BATISTA, Marta Rossetti; LOPEZ, Telê Porto Ancona; LIMA, Yone Soares de. Brasil: $1^{\circ}$ tempo modernista - 1917/29: Documentação. São Paulo: Instituto de Estudos Brasileiros, 1972.

BATISTA, Marta Rossetti. Coleção Mário de Andrade: artes plásticas. 2⿳ㅗㄹ ed. rev. e ampl. São Paulo: Instituto de Estudos Brasileiros, 1998.

BOAVENTURA, Maria Eugenia (org.) 22 por 22: a Semana de Arte Moderna vista pelos seus contemporâneos. São Paulo: Edusp, 2000.

BRITO, Mário da Silva. História do Modernismo brasileiro: antecedentes da Semana de Arte Moderna. $3^{\underline{a}}$ ed. Rio de Janeiro, Civilização Brasileira, 1971.

ESCOREL, Lilian. L’Esprit Nouveau nas estantes de Mário de Andrade. São Paulo: Humanitas/ Fapesp, 2011.

FERNANDES, Lygia, org. Mário de Andrade escreve a Alceu, Meyer e outros. Rio de Janeiro: Editora do Autor, 1968.

Klaxon: mensário de arte moderna. Edição fac-similar. Introdução: Mário da Silva Brito. São Paulo: Livraria Martins, 1972.

INOJOSA, Joaquim. O Movimento Modernista em Pernambuco. Rio de Janeiro: Gráfica Tupi, 1969.

MATTAR, Denise (org.). No tempo dos modernistas: D. Olívia Penteado, a Senhora das Artes. São Paulo: FAAP, 2002.

Semana de 22: antecedentes e consequências. Exposição comemorativa do cinquentenário. São Paulo: Masp, 1972. 